\title{
Lysosomal acid lipase deficiency
}

INSERM

\section{Source}

INSERM. (1999). Orphanet: an online rare disease and orphan drug data base. Lysosomal acid lipase deficiency. ORPHA:275761

Lysosomal acid lipase deficiency is a lipid storage disease that can result in 1) an earlyonset severe form, Wolman disease (see this term), or 2) a less severe form, cholesteryl ester storage disease (see this term), of cholesteryl ester accumulation in the body (liver, spleen, macrophages). Wolman disease is characterized by neonatal abdominal distension, major or even massive hepatosplenomegaly and calcified adrenal glands, cholesteryl ester storage disease presents with microvesicular steatosis leading to hepatomegaly and hypercholesterolaemia with subsequent liver failure and accelerated atherosclerosis. 